studies and occupations, the seeing eye was of infiniteeven fundamental-service.

After a brief résumé of the history of botany in England and an appreciation of the services rendered to the science by men like Grew, John Ray, Robert Brown and others, Sir William expressed the hope and belief that England would again attain and retain the premier place in botanical study and research, and that the botanists of Liverpool would so use their splendid opportunities as to maintain the reputation of their country. He went on to speak of the great industries which had their origin in bofanical discoveries, of the value of the science to medicine, and pointed out a fact too often overlooked that plants were intimately connected with every phase and stage of human life until, in the final act of the drama, they facilitated our decay.

After a vote of thanks to Sir William Thiselton-Dyer for his address, proposed by Sir John Brunner, M.P., and seconded by Prof. Harvey Gibson, and the pre. sentation of memorial keys to $\mathrm{Mr}$. Hartley and Sir

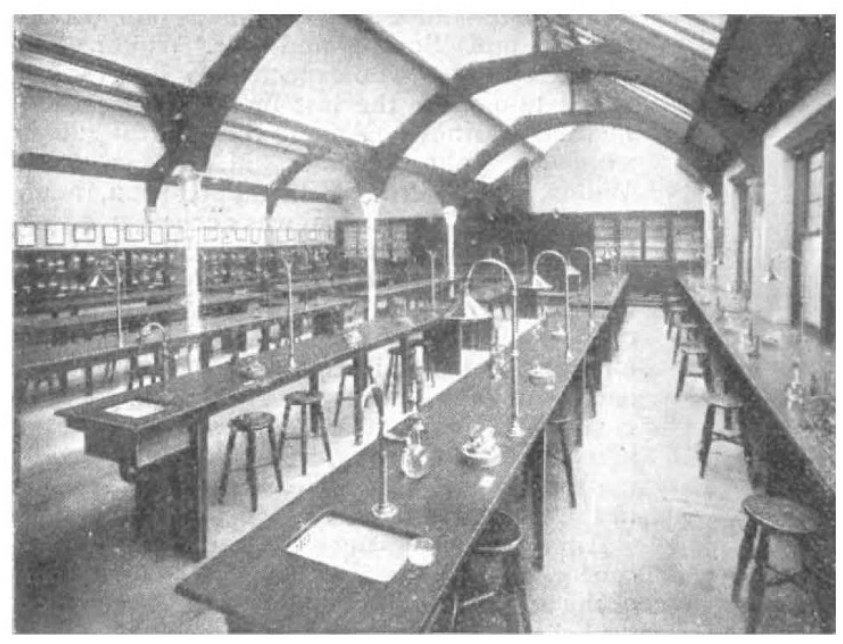

FIG. 2.-Elementary Laboratory. Hartley Laboratories, Liverpool.

William Thiselton-Dyer, the guests adjourned to the Hartley Laboratories, which were thrown open for inspection.

\section{THE HUGH MILLER CENTENARY.}

THE proposal to celebrate the centenary of the birth 1 of Hugh Miller during the present year has met with general approval, and the erection of an institute bearing his name in Cromarty has been admitted to be the best means of appropriately celebrating his memory.

It is intended that the Hugh Miller Institute shall take the form of a museum, where any relics pertaining to Miller can be kept ; and a free library and reading room.

The centenary committee have had the promise of support from Hugh Miller's admirers in America and the colonies, as well as at home, and Mr. Carnegie, the generous supporter of such institutions as the proposed institute, has made the handsome offer to give rool. for every $100 l$. raised by the committee.

It is desirable that the memorial should be as widely representative as possible, and the committee therefore appeal to all who appreciate the work accomplished by Hugh Miller in science and literature for contributions, in order that the scheme may be sufficiently advanced by the aniversary of his birth in October.

Contributions should be sent to the Treasurer, Commercial Bank, Cromarty.

$$
\text { No. I702, voL. 66] }
$$

The movement has the support of the following :--

Lord Balfour of Burleigh, Secretary for Scolland: Sir Archibald Geikie, F.R.S., LL.D. ; Prof. Masson, LL.D. ; Sir John Leng. M.P.; Sir Walter Foster, M.P. ; C. J. Guthrie, K.C., Sheriff of Ross and Cromarty; W. C. Smith, LL.B. ; Prof. Duns; Edinburgh ; A. Taylor Innes, Esq., Edinhurgh ; Prof. Clarke, State College, New York ; W. Robertson Nicol, LL. D. ; A. Bignold, Esq., M.P.; Principal Rainy, D.D.; Alexander Whyte.'D.D.; Colonel Ross. C B., of Cromarty; Mr. James Barron, Inverness Courier; W. J. Watson, B.A., Secretarv Inverness Field Clul.

$$
\text { J. Baln, Hon. Sec., }
$$

Cromarty, May, I902.

$$
\text { Hugh Miller Centenary Committee. }
$$

\section{LAZARUS FUCHS.}

THE name of Lazarus Fuchs will always be associated with the theory of linear differential equations, to which he gave an extraordinary impulse by his famous memoir published in the sixty-sixth volume of Crelle's fournal. In this paper the methods of modern function-theory are brought to bear upon the long-familiar process of solving a differential equation by series. The coefficients of the equation being supposed to be uniform analytical functions with isolated singularities, it is shown how to obtain, in the neighbourhood of an ordinary point, a complete set of independent integrals; the analytical form of these solutions is determined, and shown to depend upon a certain fundamental or indicial equation. It is proved, also, that the singularities of the integrals may be deduced from the coefficients without integration, and the notion of regular integrals is developed. The distinction is made between the integrals which involve logarithms and those which do not, and attention is drawn to those equations the integrals of which have no essential singularity. Thus in a single memoir of moderate length all the essential features of an extensive theory are presented in a clear and comprehensive outline.

In the rapid development which followed the publication of this memoir, the author naturally took a prominent part. Among his important contributions may be mentioned his researches on linear equations with algebraic integrals, on constructing linear equations the integrals of which have assigned singularities, and on equations the integrals of which are connected by algebraic relations. An instructive illustration of the general theory is given by his memoir on the equation satisfied by the elliptic integrals $K, K^{\prime}$.

When the independent variable describes a closed curve, a set of integrals undergo a linear substitution, and all the substitutions arising from different paths form a group associated with the equation. M. Poincare assigned the name of Fuchsian functions to functions invariant for a group of linear transformations of the variable in recognition of Fuchs's results concerning equations of the second order.

Fuchs's mathematical papers are very pleasant to read and free from that tendency to heaviness which is apt to belong to memoirs on differential equations. He had the faculty of bringing out clearly the really important points without over-elaborate detail, and he did not disdain to show the power of his methods by applying them to specific and definite problems. In these respects he may be compared with Halphen. While admitting that his way was prepared by the work of Cauchy, Briot and Bouquet, and Riemann, we may fairly claim for him that he has been the effective pioneer in a vast and fascinating region.

It is interesting to remember that Henry Smith, in a presidential address to the London Mathematical Society 